Modelo Classificador de Intenções com utilização de Redes Neurais Recorrentes: um estudo de caso para auxiliar os estudantes com dúvidas nas funcionalidades do AVA MOODLE

Jeferson Oliveira, FURG, icqjef@gmail.com Regina Barwaldt, FURG, reginabarwaldt@ furg.br Luiz Oscar Homann de Topin, FURG, 1topin@ gmail.com Joelson Sartori, FURG, joelsonsartori@gmail.com

Resumo: Esta pesquisa apresenta um chatbot inteligente do IBM Watson para melhorar a participação do aluno no Moodle. Redes Neurais Recorrentes foram utilizadas para gerar um modelo e classificar as intenções de 48 alunos que interagiram com o assistente. Uma rede neural foi treinada e submetida aos critérios de avaliação e obteve $99,80 \%$ dos testes de precisão. $\mathrm{O}$ assistente virtual também demonstrou capacidade de colaborar nas atividades de atendimento ao aluno nas dúvidas frequentes sobre o uso do Moodle. Este estudo apresentou evidências ser viável implementar o chatbot para auxiliar dúvidas nestes contextos.

Palavras-chave: Assistente virtual, IBM Watson, Ambiente Virtual de Aprendizagem, Redes Neurais Recorrentes.

\title{
Intent Classifier Model using Recurrent Neural Networks: a case study to help students with doubts about the functionalities of AVA MOODLE
}

Abstract: This survey features an intelligent IBM Watson chatbot to improve student participation in Moodle. Recurrent Neural Networks were used to generate a model and classify the intentions of 48 students who interacted with the assistant. A neural network was trained and submitted to the evaluation criteria and obtained $99.80 \%$ precision tests. The virtual assistant also demonstrated the ability to collaborate in student service activities. Infrequently asked questions about the use of Moodle. This study showed evidence that it is feasible to implement the chatbot to help with doubts in these contexts.

Keywords: Virtual assistant, IBM Watson, Virtual Learning Environment, Recurring Neural Networks.

\section{Introduction}

A chatbot (bot) is a virtual assistant designed to simulate a conversation using text messages, similar to the short message system (SMS). Chabot's try to simulate human activities, interacting and working with students in virtual environments (Leonhardt et al., 2003). To (Huang; Zhou e Yang, 2007), usually the interaction with a chatbot starts at the introduction of a question or sentence, after the embedded software answers the question, makes a comment or starts a new topic. According to (Schlicht, 2018), a chatbot can be defined by two types: (I) based on rules, where his answers are predefined and he cannot process information or commands to the existing specifications. For this type of chatbot, intelligence is limited by the set of rules; (II) based on AI techniques, which learn interactions with students. These chatbots use Natural Language Processing (PLN) to provide accurate and dynamic responses. Different market segments are already investing in AI, including IBM. International Business Machines (IBM) has presented updates on its Artificial Cognition Web Platform, called Watson, which allows the development of applications for different business models, including chatbots (High, 2012). This article aims to present an intelligent chatbot, developed with the cognitive services of IBM Watson, to answer the frequent doubts of students. 


\section{Chatbot in the educational context}

The Chabot's allow the collection and storage's of information exchanged with students for potential queries in the form of reports or analysis in decision making (Asher, 2017), (Silva et al., 2018). In this sense, the use of chatbots enables IES a reduction in the number of queries doubts about Moodle. Technologies to develop Chabot's include platforms defined in the cloud, such as Microsoft Azure chat and Heroku. According to (Primo, 1998), after conducting a comparative study between different web platforms for the development of chatbot, he concluded that the platforms monitored in the cloud have chronicity of intelligence. According to (Kojouharov, 2017), one of the ways to build an intelligent robot is to create a response generation model in an open domain conversation. The domain understood by chatbot in the context of learning consists of a set of frequently asked questions about the use of Moodle in the response generation domain; a chatbot can take two approaches: Recovery-based uses a repository of presets and the generating chatbots generate new responses from models.

\section{Platforms for chatbot development}

A survey was carried out to identify the leading chatbot development platforms to meet the proposal's requirements: to support text messages, multiplatform and free, according to Table 1.

Table 1. Some platforms for chatbot development.

\begin{tabular}{|c|c|c|c|c|c|c|}
\hline Features / Platform & Botpress & Dialogflow & Wit.ai & Lex & Chatfuel & IBM Watson \\
\hline Open-source & $\mathrm{X}$ & & & & & \\
\hline Customization required & $\mathrm{X}$ & $\mathrm{X}$ & $\mathrm{X}$ & $\mathrm{X}$ & $\mathrm{X}$ & $\mathrm{X}$ \\
\hline $\begin{array}{c}\text { Integrated with natural } \\
\text { language processing }\end{array}$ & $\mathrm{X}$ & $\mathrm{X}$ & $\mathrm{X}$ & $\mathrm{X}$ & & $\mathrm{X}$ \\
\hline Content management & $\mathrm{X}$ & $\mathrm{X}$ & & & $\mathrm{X}$ & $\mathrm{X}$ \\
\hline Integrates bot analysis & $\mathrm{X}$ & $\mathrm{X}$ & & & $\mathrm{X}$ & $\mathrm{X}$ \\
\hline Custom analysis & $\mathrm{X}$ & & & $\mathrm{X}$ & & $\mathrm{X}$ \\
\hline Modular architecture & $\mathrm{X}$ & & & $\mathrm{X}$ & & $\mathrm{X}$ \\
\hline Extensible & $\mathrm{X}$ & & & $\mathrm{X}$ & & $\mathrm{X}$ \\
\hline Free nip provider lock & $\mathrm{X}$ & & & & & $\mathrm{X}$ \\
\hline Available on-premises & $\mathrm{X}$ & & & & & $\mathrm{X}$ \\
\hline Available in the cloud & $\mathrm{X}$ & $\mathrm{X}$ & $\mathrm{X}$ & $\mathrm{X}$ & $\mathrm{X}$ & $\mathrm{X}$ \\
\hline GUI for non-technicians & $\mathrm{X}$ & $\mathrm{X}$ & $\mathrm{X}$ & $\mathrm{X}$ & $\mathrm{X}$ & $\mathrm{X}$ \\
\hline $\begin{array}{c}\text { Extensible dialog } \\
\text { management }\end{array}$ & $\mathrm{X}$ & & & & & $\mathrm{X}$ \\
\hline SLA available & $\mathrm{X}$ & & & & & $\mathrm{X}$ \\
\hline Voice Enabling & & $\mathrm{X}$ & & & & $\mathrm{X}$ \\
\hline $\begin{array}{c}\text { Support available } \\
\text { Multilingual }\end{array}$ & $\mathrm{X}$ & $\mathrm{X}$ & & & $\mathrm{X}$ & $\mathrm{X}$ \\
\hline $\begin{array}{c}\text { Role-based user } \\
\text { access control }\end{array}$ & $\mathrm{X}$ & $\mathrm{X}$ & & $\mathrm{X}$ & $\mathrm{X}$ \\
\hline Built-in Human-in-Loop \\
(HITL)
\end{tabular}

The chatbot receives input and forwards it to the Application module that connects to the Conversation Service Module, a container for the dialogue flow and training data. This interprets the text, directs the flow of interaction, and gathers all the information necessary to answer or execute a student transaction. The Application module has the function of making the connection between the messaging services and Watson. Finally, the Analytic module is responsible for monitoring and recording and storing interactions made with students to identify unanswered questions successfully. The architecture is shown in Figure 1 below. 


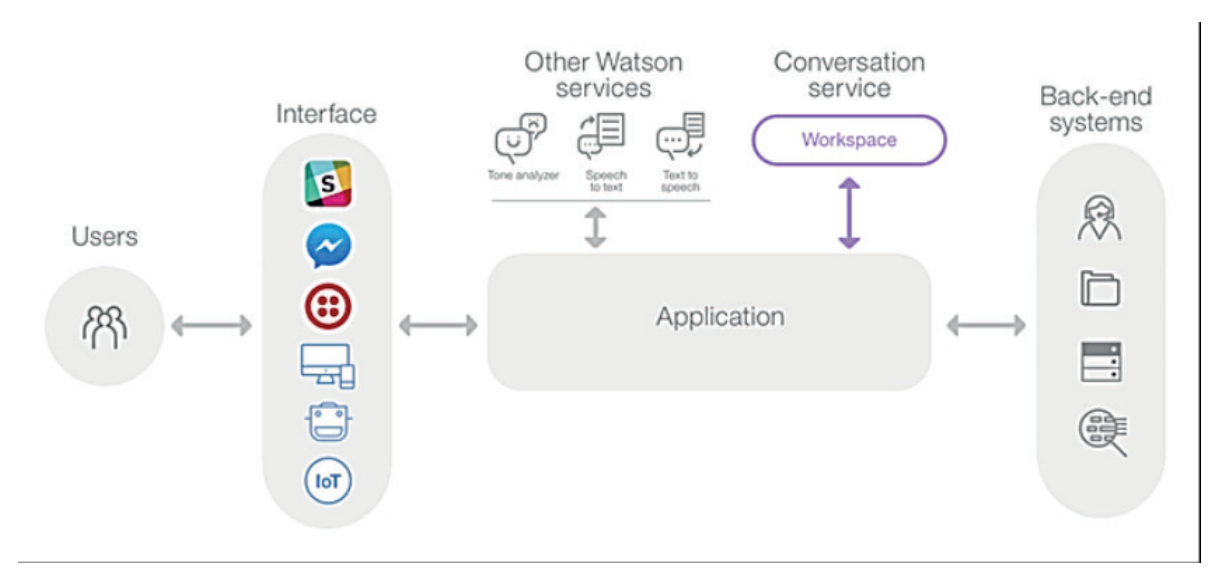

Figure 1. Watson Assistant architecture overview. Source: IBM (2019).

Then, the module for restarting the interaction is activated, and the chatbot offers to help with other questions, with: "Can I help you with anything else?" The conversation termination module is then activated, and the chatbot sends the message " At any time, you can call me," which makes it possible to restart a new interaction.

\section{Methodology for the development of chatbot}

Figure 2 shows the methodological procedures used for the development and implantation of the chatbot in the VLE.

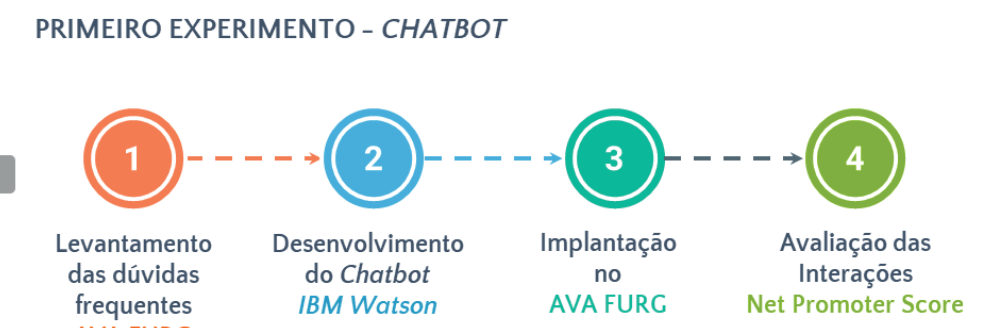

AVA FURC

Figure 2. Methodological procedures for implanting the chatbot in the VLE.

\subsection{Integration with VLE}

As the following steps were necessary to integrate the chatbot through the Facebook Messenger interface to VLE-Moodle: 1) Creation of the API for the chatbot on Facebook, to obtain the access token, its function, and to use the Watson API to read, write or modify the chatbot page data. 2) connect the chatbot to Facebook Messenger. The Messenger platform sends events to the chatbot webhook to notify you when interactions occur.

\subsubsection{Data collection and analysis}

Chatbot's interactions with students took place over four weeks; interactions were collected and analyzed in three groups: correct answers; out of contextual questions, and wrong answers. Of 14 interactions: 6 answers were correct, 6 questions out of context, and 2 unanswered. Considering only the number of right and wrong answers, we have a percentage of $75 \%$ for the correct answers and $25 \%$ for the wrong answers, for a total of eight responses. Figure 3 shows the classification of interactions. Figure 3 shows the 
classification of interactions.

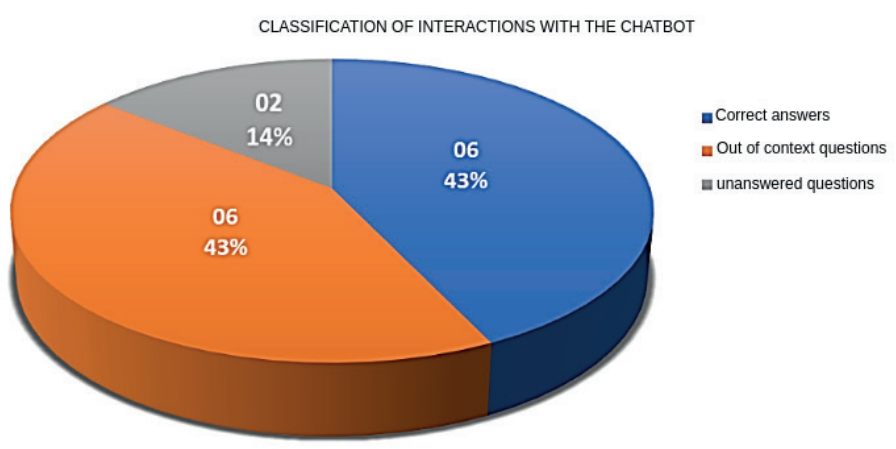

Figure 3. Classification of interactions with the chatbot.

Table 2 shows the answers separated and classified according to the categories analyzed: correct answers, incorrect answers, and out-of-context questions.

Table 2. Categorization of interactions.

\begin{tabular}{|c|c|c|}
\hline Correct answers & Out of context questions & Unanswered questions \\
\hline "Redefine password" & "Get off my screen, please" & "How to enroll in a course for the first time" \\
\hline "Moodle Tutorials" & "I want to take a tutoring training course" & "I didn't change my password or user, \\
& I can't access" \\
\hline "Log-in to Moodle" & "Good afternoon, is this course already formed?" & \\
\hline "How to send message" & "When will my post-graduate classes return?" & \\
\hline "Enroll in the discipline" & "I would like to know my number" & \\
\hline "Submit task" & "How do I get a card?" & \\
\hline
\end{tabular}

Figure 4 below shows the number of users who interacted with the chatbot in the four weeks of use.

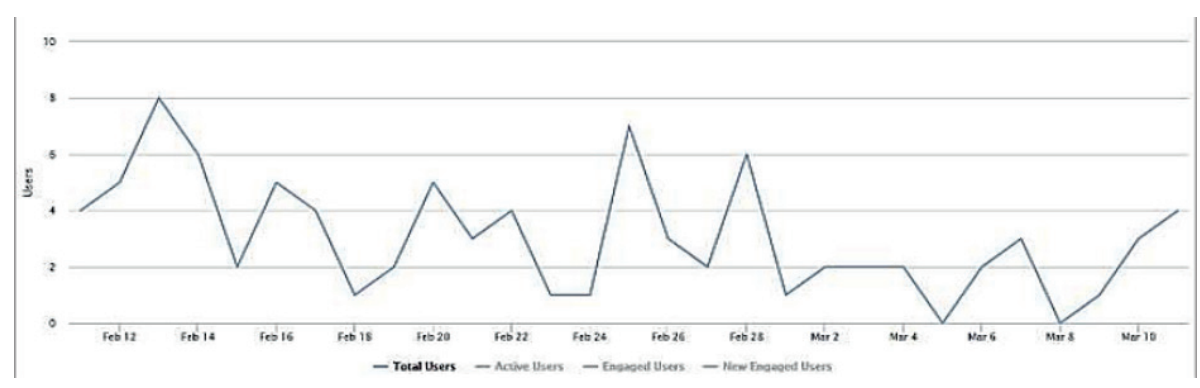

Figure 4. Some students were interacting with the chatbot in the four weeks.

\subsubsection{IBM WATSON application}

The student has access to the VLE Moodle Web Interface in the proposed architecture through a computer or mobile device. VLE adds the use of technologies such as HTML, CSS, JavaScript, and PHP. The application was hosted on the IBM Cloud, making it a full web service, a knowledge base was developed using the "Knowledge Data-Watson" module, to answer the questions prepared by the students, the chatbot uses the "Watson API" to integrate with the chosen channel, in this case, Facebook Messenger. The chatbot training was carried out by observing the closed contexts of the subjects defined in the first chatbot so that it was possible to repeat the questions of the conversations that did not obtain correct answers. Figure 5 shows the implemented chatbot. 


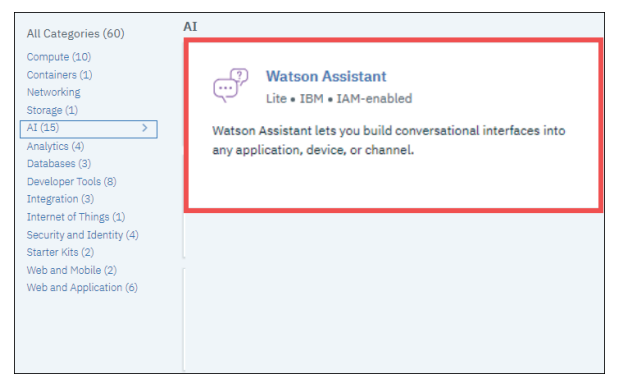

Figure 5. Chatbot creation panel

Figure 6 shows the intent configuration panel that the chatbot has been trained to recognize. In item 1, the name assigned to the node related to the context created is displayed. Item 2 shows an intention created; below, item 3 shows some examples of students' possible questions.

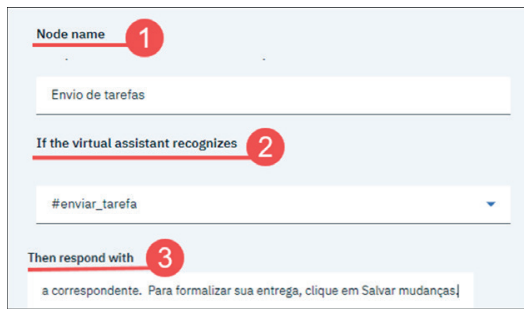

Figure 6. Defining chatbot intentions.

Figure 7 shows the intentions and responses created in the dialogue, in this phase, the chatbot was trained. In the end, the chatbot is ready to be used.

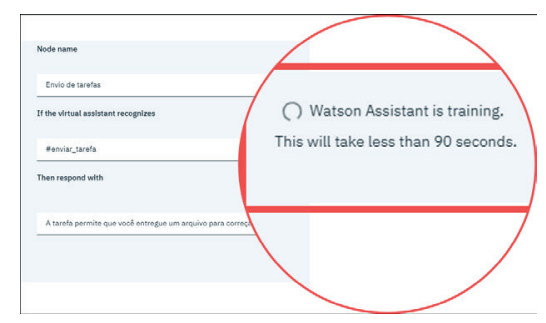

Figure 7. Chatbot training.

\section{Intent classifier model}

According to (Maheshwari, 2019), a text classification model, in general, consists of the fallowing steps: training, resources vector, markers, machine learning algorithm.

\subsection{Data preparation}

Each intention contained in the data set was mapped to a real vector domain, according to (Lai et al., 2015). For this experiment, the vectors had a size of 20, 3000 most relevant terms were selected from the total number, and finally, the number of terms in each revision of the variable, the limits were revised to 100 words, truncating lengthy revisions and filling shorter corrections with zero values. In the vectorization of intentions, the Keras library was used. Finally, the column named activity type was the training target, as it contains the categories of purposes registered on the teaching platform. Figure 8 shows the attributes contained in the dataset. 
Figure 8. Stages for classification of intentions. Source: Open University Learning Analytics dataset

\subsection{Proposed architecture}

The architecture adopted in work is the recurrent neural networks, following the model (Segatto e Coury, 2006). 20 vectors form the first input layer to represent the 20 most relevant intentions. The second hidden layer comprises 14 nodes and houses the S2S layer, which uses 100 storage memory units. This layer is responsible for keeping the state of the time series. The output layer generates 20 output values, one for each class of intention. Table 3, below, presents an overview of the proposed RNN model.

Table 3. Overview of the proposed RNN model. Source: author.

\begin{tabular}{|l|l|l|l|l|l|}
\hline Architecture & Layers & Nodes & F.Activation & F.Loss - EQM & Algorithm \\
\hline S2S & 3 & $20 / 14 / 20$ & Softmax & Cross-Entropy & ADAM \\
\hline S2S: Step-By-Step Architecture \\
MSE: Main Square Error \\
ADAM: Adaptative Moment Estimation Algorithm \\
\hline
\end{tabular}

\subsection{RNN Training}

The model has about 100 neurons in the first layer, totaling 1,000,000 parameters. The second layer presents 100 neurons concluding with 80,400 parameters. Finally, the third and last layer was applied to 20 neurons, leaving 1,082,420 parameters to be estimated. The classifier model used a supervised learning approach. The summary of training data can be seen in Figure 9.

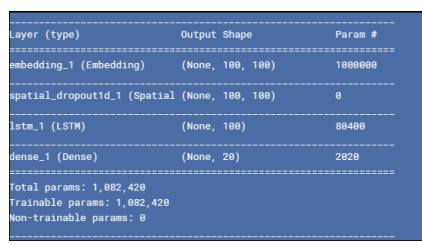

Figure 9. Model created for training the network.

The model was subjected to two tests: the first was adopted with the function $=$ 0.001 and the second, with the function $=0.5$. Finally, the Adaptive Moment Estimation Algorithm (Adam) was chosen to optimize the training, integrating the adaptive learning rate and the moment. In the experiments carried out, the data set was subdivided into two datasets: the first with $90 \%$ of the data used for training the artificial neural network. The other with $10 \%$ was reserved for testing and validating the network, according to the table 4.

Table 4. Dataset splitting.
\begin{tabular}{|l|l|}
\hline Training & Test \\
\hline $5.727,0$ & 637,0 \\
\hline
\end{tabular}

The criteria for evaluating the results (Revocation, Precision, Failure, Precision) were in accordance with (Oliveira et al., 2019). 


\section{Results}

To understand the level of satisfaction of the students who interacted with the chatbot, the Net Promoter Score (NPS) methodology (Keiningham et al., 2007) was used. Table 5 shows each degree of satisfaction classified according to the method.

Table 5. Categorization of interactions.
\begin{tabular}{|l|l|}
\hline Classification zone & NPS \\
\hline Excellence & between 76 and 100 \\
Quality & between 51 and 75 \\
Improvement & between 1 and 50 \\
Review & between -100 and 0 \\
\hline
\end{tabular}

At the end of the interactions with the chatbot, students were invited to evaluate the virtual assistant's service through a questionnaire. The quality of the chatbot responses reached an average of 3.85 points, on a scale of 1 to 5, with 1 representing" Terrible" and 5 representing "Great," the standard derivation was 0.84 points. With that, we realized that the students, for the most part, were satisfied with the virtual assistant's responses during an interaction performed. As for the level of satisfaction with the service provided by the chatbot, the results indicate that the 48 responses counted were obtained, $01(2.08 \%)$ answered as "dissatisfied," and 15 (31.25\%) were" delighted" with the service. The students were separated and classified according to the number of votes couted, as shown in Table 6.

Table 6. Categorization of interactions.

\begin{tabular}{|l|l|l|l|}
\hline Evaluation & Level & Amount & Classification(\%) \\
\hline 5 & excellent & 15 & 32,0 \\
4 & very good & 23 & 48,0 \\
3 & good & - & - \\
2 & reasonable & 1 & 2,0 \\
1 & bad & - & - \\
0 & terrible & - & - \\
\hline
\end{tabular}

48 students answered the survey. To obtain the NPS satisfaction level, it is necessary to calculate the difference between the Promoter and Detractor classification percentages. In this case, as the Detractor index was equaled to 0, evaluation with indexes 0 or 1 was not counted.

$$
\text { NPS }=\frac{\text { Promoters }- \text { Detractors }}{\text { Total }} * 100
$$

Calculating the NPS for this number of responses, the value of $76.60 \%$ is obtained. The calculation is shown below.

$$
N P S=\frac{37-1}{47} * 100=76.60 \%
$$

With the NPS equal to $76.60 \%$, the logo or the virtual assistant's attendance was classified as excellent, according to Table 7 . Of these, 03 responses were selected, as they are relevant to the work. The first answer suggests a mandatory interaction with the chatbot at the user's first access to the VLE platform, a second answer that can change the interface. Finally, the last suggestion to expand the context of matters to which the assistant can respond. As the responses are selected in Table 6, follow and help improve chatbot.

The main performance measures in neural networks were used to validate the neural network: Accuracy, Precision, Recall, and F1 Score. In the graphs of Figure 10 
Table 7. Chatbot improvement suggestions.

\begin{tabular}{|l|l|}
\hline \multicolumn{2}{|c|}{ What are your suggestions for improving the chatbot? } \\
\hline 01 & $\begin{array}{l}\text { I think could criticize or create a simple design of the robot's image, } \\
\text { but there is no reason to change it, the system works very well and seems to } \\
\text { be more of an VLE guide than a "problem solver". I could suggest a mandatory } \\
\text { first login interaction just to make it more famous and a reference to be a "problem solver". }\end{array}$ \\
\hline 02 & It could have a better interface. \\
\hline 03 & More varieties of subjects can be placed for the user who asks and answers their questions. \\
\hline
\end{tabular}

below, two performance tests of the network can be observed. Along with the iterations, the training algorithm's accuracy increases with each passing season and then stabilizes. The trained network (graph a) achieved the best training performance after executing 5 epochs when configured (graph b); the same network needed 19 epochs to converge and stabilize.
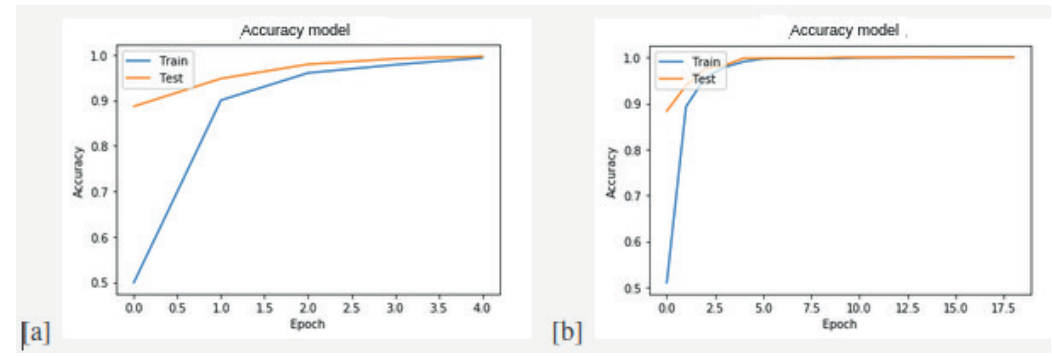

Figure 10. Validation accuracy of RNN.

The values selected by the optimization algorithm were as follows: 100\% (above) and $99.9 \%$ (above); that is, the model displayed promising results in identifying the intentions present in the dataset. However, only with the accuracy value, it is not possible to affirm the quality of the network performance since the metric can classify false positives as correct, producing an inconsistent result. For this reason, other performance metrics were used, the values obtained in performance metrics. (Precision, Recall and F1 Score) show in Table 8.

Table 8. Metrics obtains - Training set

\begin{tabular}{|l|l|l|l|l|}
\hline Function $\alpha$ & Accuracy & Precision & Recall & F1 Score \\
\hline 0,001 & 0.99800 & 0.82111 & 84279 & 0.83181 \\
0,5 & 1.00000 & 0.83268 & 0.84712 & 0.83984 \\
\hline
\end{tabular}

Then, the confusion matrix was generated using the values obtained with the performance metrics Table 8 and comparing with the values achieved by a neural network optimization algorithm. The generated matrix is shown in Table 9 below.

Table 9. Generate confusion matrix
\begin{tabular}{|l|l|l|}
\hline TP & 2093 & 432 \\
TN & 388 & 2150 \\
\hline TP: True positive \\
TP: True negative \\
\hline
\end{tabular}

The lowest values obtained from the set of tests indicate that the accuracy of the model reached more than $83.0 \%$ of correct answers. The precision received more than $84.0 \%$, the recall reached around $83.0 \%$ and F1 Score was around approximately $84.0 \%$. The adjustments performed on the network change the function's values that suffer little 
difference in the network, or those that lead to the conclusion that the margin of error reached is acceptable in both cases. The selected values can be shown in Table 10 below.

Table 10. Metrics obtained - Test set

\begin{tabular}{|l|l|l|l|l|}
\hline Function $\alpha$ & Accuracy & Precision & Recall & F1 Score \\
\hline 0,001 & 0.83804 & 0.84361 & 82891 & 0.83619 \\
0,5 & 0.99487 & 0.83767 & 0.81544 & 0.90953 \\
\hline
\end{tabular}

The result of the interaction is show in Figure 11. Example of one of the questions submitted to the bot: 1- "como me inscrevo em um curso pela primeira vez". Then, the chatbot identifies the student's intention: 2 - "Disciplinas" and return with the answer,3, corresponding:

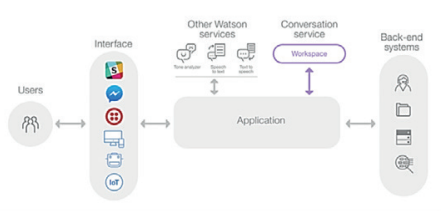

Figure 11. The panel of recognition of intentions.

Figure 12 below shows the chatbot interactions on the Facebook Messenger interface. In the tests performed, the visual assistant was able to adequately answer the questions not answered in the first interactions.

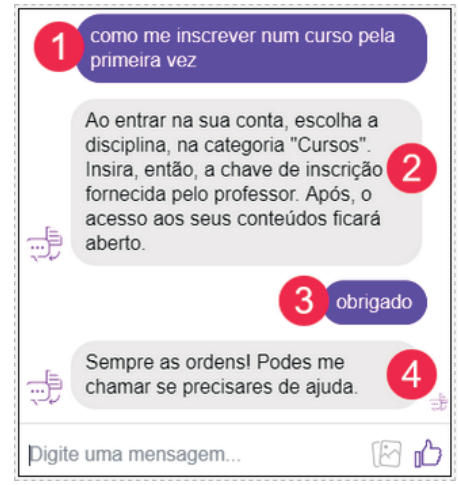

Figure 12. Chatbot integrated with Facebook Messenger

Regarding the interaction in the VLE, the results showed that the chatbot, in its scope, obtained satisfactory results in the identification of the student's intentions. Regarding the satisfaction of use by the students, he obtained the highest score in his evaluation. In the experiment that analyzed the efficiency of the RNN in the classification of intentions, the results demonstrated remarkable rates of correct answers.

\section{Conclusion}

This work presented the implementation of an IBM Watson intelligent educational conversation chatbot in the AVA Moodle integrated with MSN Messenger, to help in the use of the tools available to students at a public university in the south of the country in relation to the support material provided by teachers in the environment, using artificial intelligence techniques. As expected, the virtual assistant demonstrated the ability to collaborate in student service activities on frequently asked questions in the AVA Moodle, and the improvement to serve the academic community where the potential of these 
applications in the educational scenario was viable, allows paradigms to be able to be gradually changed and bring the necessary improvements to the current context, where attendance has increased significantly in relation to remote activities, in this case it contributes to the waiting time for students, especially those who do not have previous knowledge. The project is currently submitted to the new criteria of evaluation tests, precision and increment with intentions of answers and option of the bot to interact in LIBRAS with deaf students.

\section{References}

Asher, N. A warmer welcome: Application of a chatbot as a facilitator for new hires onboarding. 2017.

High, R. The era of cognitive systems: An inside look at IBM Watson and how it works. IBM Corporation, Redbooks. 2012.

Huang, J.; Zhou, M.; Yang, D. Extracting chatbot knowledge from online discussion forums. In: IJCAI. [S.1.: s.n.], 2007. v. 7, p. 423-428.

Keiningham, T. L.; Cooil, B.; Andreassen, T. W.; Aksoy, L. A longitudinal examination of net promoter and firm revenue growth. Journal of Marketing, SAGE Publications Sage CA: Los Angeles, CA, v. 71, n. 3, p. 39-51, 2007.

Kojouharov, S. Ultimate bot design guide - a living doc. 2017.

Lai, S.; Xu, L.; Liu, K.; Zhao, J. Recurrent convolutional neural networks for text classification. In: Twenty-ninth AAAI conference on artificial intelligence. [S.l.: s.n.], 2015.

Leonhardt, M.; Castro, D. Dorneles de; Dutra, R. D. S.; Tarouco, L. R. um chatterbot para uso em ambiente educacional. II Ciclo de Palestras sobre Novas Tecnologias na Educaçao, 2003.

Maheshwari, A. Report on text classification using cnn, rnn han. Medium, 2019.

Oliveira, J. da S.; Espíndola, D. B.; Barwaldt, R.; Ribeiro, L. M.; Pias, M. Ibm watson application as faq assistant about moodle. In: IEEE. 2019 IEEE Frontiers in Education Conference (FIE). [S.1.], 2019. p. 1-8.

Primo, A. F. T. Interaçãomútua e interação reativa: uma proposta de estudo. In: Recife, XXI Congresso da Intercom. [S.1.: s.n.], 1998.

Schlicht, M. The complete beginner's guide to chatbots-chatbots magazine. URL: https://chatbotsmagazine. com/the-complete-beginner-s-guide-tochatbots-8280b7b906ca. Accessed, v. 26, 2018.

Segatto, E.; Coury, D. Redes neurais artificiais recorrentes aplicadas na correção de sinais distorcidos pela saturação de transformadores de corrente. Sba: Controle \& Automação Sociedade Brasileira de Automatica, SciELO Brasil, v. 17, n. 4, p. 424-436, 2006.

Silva, M.; Melo, S. de; Silva, M.; Lima, L. Integração de um agente conversacional no processo de ensino e aprendizagem utilizando as teorias mce e mmeeb para a retenção do conhecimento. In: Brazilian Symposium on Computers in Education (Simpósio Brasileiro de Informática na Educação-SBIE). [S.1.: s.n.], 2018. v. 29, n. 1, p. 99. 